\title{
Avaliação histológica do polímero derivado do óleo de mamona (Ricinus communis) aplicado na diáfise proximal da tíbia de cães
}

\section{Histological evaluation of polymer derived from castor oil bean (Ricinus communis) in the tibia proximal diaphase in dogs}

\author{
Edilaine Sarlo Fernandes, ${ }^{*}$ Andréa Pacheco Batista Borges, ${ }^{* *}$ Marlene Isabel Vargas Viloria, ${ }^{* *}$ \\ Luiz Gonzaga Pompermayer, ${ }^{* * *}$ Cristiane Torres Neto, ${ }^{* * * *}$ Cleber Barbosa de Oliveira ${ }^{* * * * *}$
}

\begin{abstract}
Resumo
O presente trabalho teve por objetivo avaliar histologicamente a biocompatibilidade e osteointegração do polímero derivado do óleo de mamona (Ricinus communis) usado como substituto no preenchimento de falha óssea, provocada na diáfise proximal da tíbia de cães. Foi realizado um estudo experimental utilizando-se 20 cães, clinicamente sadios, que foram separados em dois grupos de dez cada. O grupo 1 recebeu tratamento com a poliuretana de mamona (PDOM) e o grupo 2, sem tratamento, foi utilizado como controle. Retirou-se um fragmento ósseo na tíbia com cerca de $10 \times 5 \mathrm{~mm}$ de tamanho e a falha óssea provocada foi preenchida no grupo $1 \mathrm{com}$ a poliuretana derivada do óleo de mamona. Para análises histológicas, dois animais de cada grupo foram eutanasiados aos oito, 30, 60, 120 e 180 dias após a cirurgia. No exame histológico não foi obsevada integração do PDOM no grupo tratado. O reparo do defeito dos animais do grupo controle ocorreu aos 30 dias. Não foi observada reação tipo corpo estranho nem completo reparo dos defeitos tratados com o polímero.
\end{abstract}

Palavras-chave: substitutos ósseos, biocompatibilidade, poliuretana de mamona.

\begin{abstract}
The present work evaluated the biocompatibility and osseointegration of the polymer derived from castor oil bean (PDOM) as a bone substitute in the repair of bony defects in the tibia proximal diaphase in dogs. This experimental sudy was carried out with 20 clinically heathy dogs, divided in two groups consisting of 10 dogs each. One group had the $10 \times 5 \mathrm{~mm}$ defect completely filled with PDOM and the other did not receive any treatment, used as control. Material from two animals of each group were collected in days eight, 30,60, 120 and 180 after surgery for histological analysis. At the histological exam, a no integration of PDOM was observed in the treated group. In the control group, the bone repair ocurred at 30 days after surgery. During the experiment no foreign body reaction was observed, neither a complete filling of the bony defect in the animals treated with PDOM.
\end{abstract}

Keywords: bone substitute, biocompatibility, polymer derived from castor oil bean.

\section{Introdução}

Em conseqüência do desenvolvimento social e urbano, os traumatismos são cada vez mais freqüentes, ocasionando fraturas que apresentam perda de quantidade substancial de osso. Assim, a busca por técnicas alternativas que permitam a osteogênese, osteoindução e osteocondução torna-se necessária. É com este intuito que os pesquisadores buscam técnicas que auxiliem na regeneração dos tecidos e órgãos, restabelecendo-Ihes as funções fisiológicas. Em alguns pacientes, a função é restaurada apenas com a regeneração tecidual, mas, em outros, é necessário o uso de próteses (Ignácio, 1999).
Biomateriais, usados como substitutos ósseos, devem apresentar determinadas propriedades físico-químicas compatíveis com a fisiologia do osso (Najjar et al., 1991), sendo que a procura por novas substâncias tem se mostrado um campo muito fértil para pesquisas biológicas, incluindose os poliuretanos, um dos principais polímeros deste século (Araújo, 1998).

Em meados da década de 1980, o Prof. Dr. Chierice descobriu um polímero vegetal derivado do óleo de Mamona (Ricinus communis). Após alguns testes incipientes, verificou-se a biocompatibilidade e atoxicidade deste polímero (Ohara et al., 1995).

\footnotetext{
*Médica-veterinária, mestre, professora da AGROPLAC- GAMA-DF; Autônoma Clínica Veterinária Arca de Noé - Brasília, DF. CEP 78000-000. Autor para correspondência. E-mail: edilainesf@bol.com.br.

**Médica-veterinária, doutora, professora adjunto do Departamento de Veterinária da UFV - Viçosa, MG - CEP 36571-000.

***Médica-veterinária, doutora, professora adjunto do Departamento de Veterinária da UFV - Viçosa, MG - CEP 36571-000.

**** Médico-veterinário, doutor, professor adjunto do Departamento de Veterinária da UFV - Viçosa, MG - CEP 36571-000.

${ }^{* \star \star \star \star}$ Médica-veterinária, aluna do curso de Especialização de Pequenos Animais - Departamento de Veterinária da UFV - Viçosa, MG - CEP $36571-000$.

${ }^{\star * \star \star * *}$ Médico-veterinário, mestre, doutorando UNESP - Jaboticabal, SP.
} 
A tendência mundial à procura de materiais biodegradáveis, não-poluentes e derivados da biomassa fez com que as pesquisas com polímeros derivados de óleo de mamona (PDOM), se tornassem um tema atual, abrindo assim novas perspectivas para seu desenvolvimento (Araújo, 1998).

O presente trabalho teve por objetivo avaliar a biocompatibilidade e osteointegração do polímero derivado do óleo da mamona (Ricinus communis), como substituto ósseo no preenchimento de falhas, provocadas na diáfise proximal da tíbia de cães.

\section{Material e métodos}

No estudo foram utilizados 20 cães, com idade entre 2 e 4 anos, machos e fêmeas, clinicamente sadios, com estrutura óssea tibial normal, pesando entre 8 e $18 \mathrm{~kg}$, provenientes do canil experimental do Departamento de Veterinária da Universidade Federal de Viçosa. Os animais foram separados em dois grupos de igual número (tratado e controle) e alojados em canis coletivos onde receberam ração comercial, duas vezes ao dia e água à vontade.

Após jejum de 12 horas, foi utilizado em todos os animais no protocolo anestésico, que constou de acepromazina ${ }^{1}(0,1 \mathrm{mg} /$ $\mathrm{kg} / \mathrm{IV}$ ) como medicação pré-anestésica e pentobarbital sódico a $3 \%^{2}$ em dose suficiente para indução e manutenção anestésica durante o tempo cirúrgico.

No membro pélvico esquerdo de todos os animais, após tricotomia e antissepsia de rotina, foi feita a exposição da diáfise proximal medial da tíbia esquerda, por incisão longitudinal da pele e tecido subcutâneo da região, segundo Piermattei e Greeley (1988), evidenciando, desta maneira, a parte do osso interessada, sendo o periósteo incisado e descolado. Posteriormente, foi delimitado, com auxílio de perfurador ortopédico elétrico e brocas de $1,5 \mathrm{~mm}$, um fragmento retangular de aproximadamente $10 \mathrm{~mm} \times 5 \mathrm{~mm}$ de tamanho, até atingir o canal medular. Este fragmento foi retirado da tíbia, com auxílio de um osteótomo e martelo e a lesão foi preenchida, no grupo tratado, com PDOM em grânulos compactos e no outro grupo a falha permaneceu sem qualquer preenchimento, sendo utilizado como controle. Os tecidos incisados foram suturados de maneira convencional.

Para análises histológicas, dois animais de cada grupo foram eutanasiados aos oito, 30,60, 120 e 180 dias de pósoperatório e por secção transversal da tíbia, foram obtidas amostras do local da falha óssea, com cerca de $2 \mathrm{~cm}$ de extensão. Foram fixadas em formol neutro tamponado a $10 \%$ durante 40 dias. Os fragmentos foram descalcificados em ácido fórmico a 10\%, tamponado com citrato de sódio para $\mathrm{pH} 4,5$, sob vácuo moderado, com duração média de 90 dias, quando, então, foram lavados em água corrente durante 24 horas, desidratados em álcool 70, 80 e 90\% por 24 horas, em cada e em álcool $100 \%$ por 24 horas com uma repetição e

\footnotetext{
1 - Acepran 0,2\% - UNIVET S.A. - Indústria Veterinária

2 - Pentobarbital sódico a $3 \%$
}

diafanizadas em dois banhos de xilol, por duas horas cada. Em seguida foram embebidos em parafina e mantidos em estufa, a $58^{\circ} \mathrm{C}$ durante uma noite e, então, incluídos. A seguir, cortes de 5 micra de espessura foram obtidos em micrótomo de rotação e montados em lâmina de vidro. De cada bloco de parafina foram obtidas duas lâminas, coradas pela técnica de hematoxilina-eosina e observadas ao microscópio óptico (Luna, 1968). Nas análises das secções histológicas, foram considerados: regeneração tecidual, com base nos graus de necrose óssea nas bordas do defeito, proliferação e diferenciação celular no tecido cicatricial, formação óssea, incorporação do PDOM ao osso e sua desintegração e maturação do osso novo.

Foi feita análise descritiva dos resultados, considerando o padrão de reparação óssea, qualificando, desta maneira, a presença ou não de indução óssea, a biocompatibilidade e a osteointegração do polímero.

\section{Resultados}

Ao exame histológico dos fragmentos de tíbia dos animais tratados com o polímero derivado do óleo de mamona, constatou-se em dois animais eutanasiados aos oito dias de pós-operatório, em dois aos 30 dias e em um aos 60 dias 0 deslocamento do implante para o canal medular.

Aos oito dias a falha mostrou-se parcialmente preenchida com tecido de granulação, contendo poucas células mononucleares (Figura 1A), enquanto que aos 30 e 60 dias o tecido observado na falha era predominantemente fibroelástico (Figura 1B). Ao redor do polímero observou-se a formação de cápsula de tecido conjuntivo fibroso (Figura 1B), não sendo notada a presença de osteoclastos nem células gigantes do tipo corpo estranho. Além disto, não foi observada a formação de túneis vasculares no interior do polímero. Entretanto, em um caso, observou-se um osteoclasto próximo ao implante (Figura 1C). No grupo controle foram evidenciados tecido conjuntivo frouxo e tecido ósseo neoformado. A reparação da falha se deu a partir dos 30 dias, com tecido ósseo trabecular preenchendo toda a falha.

Aos 120 e 180 dias a falha ainda estava presente nos animais do grupo tratado, com pouco crescimento ósseo de origem periosteal (um animal) e muito tecido conjuntivo próximo ao polímero (Figura 1D). Em um animal do grupo tratado, aos 120 dias, observou-se um pequeno fragmento de polímero sobre o qual havia crescimento de osso novo, porém, somente em uma pequena área havia túnel vascular adjacente ao polímero, e raras células osteogênicas (osteoblastos) podiam ser observadas (Figura 1E). No mesmo período, os animais do grupo controle já apresentavam tecido ósseo maduro na falha óssea.

Aos 180 dias, no grupo tratado observou-se uma fina cápsula de tecido conjuntivo fibroso ao redor dos fragmentos do polímero (Figura 1F).

Durante o experimento, não se observou reação do tipo corpo estranho, nem o preenchimento completo do defeito ósseo nos animais tratados com polímero derivado do óleo de mamona, à diferença do grupo controle, onde houve reparação total. 


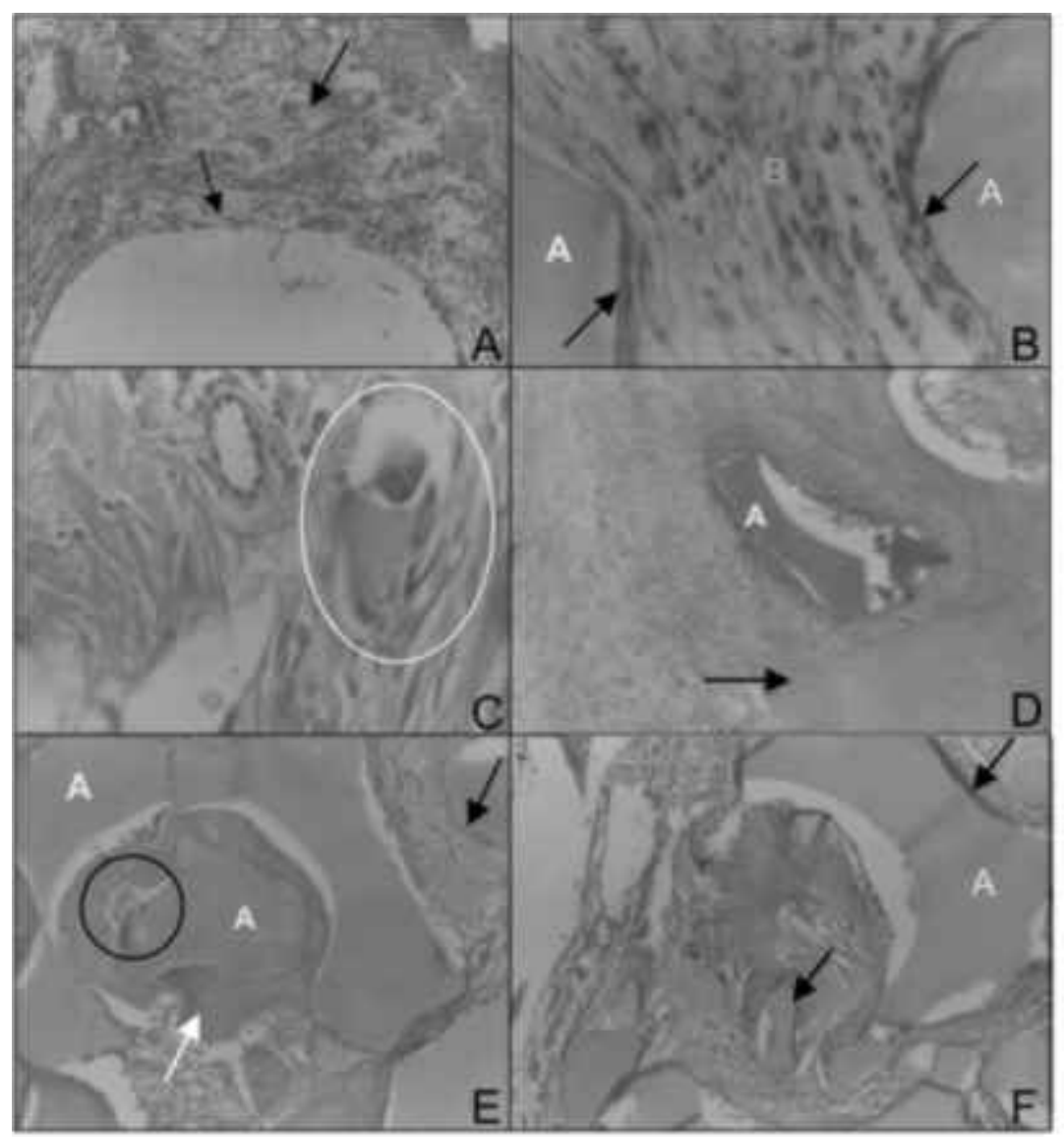

Figura 1: Corte longitudinal da região da falha óssea em cão do grupo tratado com PDOM. A. Oito dias após a cirurgia. Presença de tecido de granulação e células mononucleares (seta) preenchendo parcialmente a falha. HE, 160X. B. 60 dias após a cirurgia. Presença de tecido fibroelástico compondo fina cápsula (seta) ao redor do polímero (A) HE, 400X. C. 60 dias após a cirurgia. Observa-se um fragmento da poliuretana e um osteoclasto adjacente (círculo). HE, 400X. D.120 dias após a cirurgia. Crescimento de osso novo (seta preta) próximo ao fragmento de polímero (A). HE, 160X. E.120 dias após a cirurgia. Fina cápsula de tecido conjuntivo fibroso (seta preta) ao redor do polímero (A), formação de túnel vascular (círculo) e crescimento de osso novo (seta branca). HE, 400X. F.180 dias após a cirurgia. Fina cápsula de tecido conjuntivo fibroso (seta preta) ao redor dos fragmentos de polímero (A).

\section{Discussão}

As características do PDOM citadas por Ohara et al. (1995), Carvalho et al. (1997), Ignácio et al. (1997), Silva (1997), Araújo (1998), Ignácio (1999) determinaram sua utilização nesse modelo experimetnal; além disso, envolve tecnologia nacional, baixo custo e matéria-prima natural, existente em abundância no Brasil.

Ota (1989) atribuiu grande importância à porosidade dos implantes oriundos do polímero, pois observou crescimento ósseo através desses implantes. Tal fato poderia ser relevado em ortopedia, pois vários autores (Ignácio, 1995, Vilarinho et al., 1996, Ignácio, 1999, Accetturi et al., 2000) utilizaram implantes porosos com excelentes resultados. Entretanto, este fato não foi confirmado no presente experimento, pois, apesar do polímero estar na forma de grânulos compactos, isto não facilitou o crescimento ósseo em seu interior.

Osteointegração foi definida por Lamano Carvalho et al. (1997b) como uma estrutura conectiva direta e funcional entre o osso organizado e a superfície do material implantado e tal característica também foi atribuída ao polímero de mamona por Nácul et al. (1998). Ignácio (1995) e Lamano Carvalho (1997a) observaram osteocondução. Fato contrário foi observado neste experimento, já que com todos os métodos de análise utilizados, não se observou a reparação da falha, nem a interação polímero-osso.

Oliveira et al. (1995) notaram ausência de reação inflamatória e formação parcial de tecido ósseo no grupo tratado, em contraste com o grupo controle que teve formação óssea total. Tal fato condiz com os resultados deste experimento, no qual a formação óssea do grupo controle também foi total. No grupo tratado com PDOM, não se observou reparação do defeito (Figura $1 \mathrm{~A}$ ), sugerindo, assim, o retardamento da reparação óssea induzido pelo polímero.

Os resultados obtidos foram diferentes dos verificados por Ohara et al. (1995), no que se refere à interação entre o PDOM e o tecido ósseo, já que durante o período experimental, estava rodeado por fina cápsula de tecido conjuntivo fibroso (Figura 1F) e, por vezes, observaram-se fendas que o isolavam dos tecidos adjacentes.

O implante de polímero preencheu a cavidade formada e permaneceu biocompatível, porém interferiu com a reparação óssea, fato também observado por Ignácio (1999), indicando que o material comportou-se como um espaçador biológico, apesar de interferir no processo de reparação óssea. Outro fato observado foi a presença de osteoblastos nas adjacências do polímero quando este se apresentava em fragmentos menores, demonstrando ação das células da linhagem osteogênica sobre o implante quando se apresentava com dimensões menores.

A não-reabsorção da poliuretana de mamona, também observada por Lamano Carvalho et al. (1997a,b) e Accetturi et al. (2000), foi confirmada pela sua presença aos 180 dias de observação. No experimento de Teixeira (1995) e nos de Lamano Carvalho et al. (1997a,b) houve osteogênese progressiva com a presença de raros osteoblastos e encapsulamento dos grânulos do polímero por uma fina cápsula de tecido conjuntivo fibroso nas primeiras seis semanas. A ausência de reparação óssea, neste experimento, pode ser devida à diferença dos tipos de polímero utilizado, haja vista que alguns autores utilizaram o polímero associado ao carbonato de cálcio, no qual se observou após sua implantação, uma maior regeneração óssea.

A presença de células inflamatórias nos períodos iniciais de implantação, com predomínio de mononucleares e regressão no decorrer do experimento, foi observada em camundongos por Vilarinho (1995), Vilarinho et al. (1996), Costa et al. (1997). O mesmo fenômeno ocorreu nos cães deste experimento e, apesar de tratar de espécies diferentes, acredita-se que a presença dessas células reflete o processo inflamatório decorrente do trauma cirúrgico (Figura 1E). 
Os resultados histológicos deste experimento confrontam, de um certo modo, os achados de Lamano Carvalho et al. (1997a,b), que observaram células da linhagem osteogênica e indícios de formação de cápsula conjuntiva e reparação óssea. Nos implantes na tíbia de cães, houve formação de cápsula fibrosa (Figura 1F), presente até os 180 dias de pósoperatório, sem a presença de reparação. Concordando com os resultados de Caruzo et al. (1995) que citam a longa persistência do material e o retardamento da reparação óssea. Percebe-se, portanto, que o polímero não possui ação osteocondutora nem osteoindutora.

Chierice (1994) e Araújo et al. (1996) relataram que a mamona é identificada pelo organismo como um lipídio, exigindo um processo enzimático para a regeneração tecidual, sendo

\section{Referências}

ACCETTURI, E., ACCETTURI, F., GOLDONI, P.R. Polímero de mamona utilizado na reconstrução de rebordo alveolar, como substituto dos enxertos mucogengivais. Disponível em: http: www2.mn.zaz.com.br/medstar/casoodont.htm, p. 1-2, 2000.

ARAÚJO, C.A.C.A., TEÓFILO, J.M., BRETEGANI, L.G. Cronologia do reparo alveolar do rato após implante de Ricinus communis. S.B.Pq.O.I.A.D.R. , 1996.

ARAÚJO, L.C.R. Contribuição ao estudo dos polímeros flexíveis derivados do óleo de mamona determinando suas propriedades físicas e químicas. Tese de Doutorado. Instituto de Química de São Carlos. São Carlos. 1998. 103 p.

CARUZO, S. L. Implantes de resina poliuretana vegetal em arco zigomático de ratos - estudo histológico. Anais - $9^{\mathrm{a}}$ Jornada Acadêmica de Araraquara. Unesp, p. 116, 1995.

CARVALHO, T. L.; ARAÚJO, C. A.;TEÓFILO, J. M.; BRETEGANI, L. G. Histologic and histometric evaluation of rat alveolar wound healing around polyurethane resin implants. Maxillofacial surgery. v. 2, n. 26, p. 149-152, 1997.

CHIERICE, G. O. Pesquisa e desenvolvimento de biomateriais, baseados em poliuretanos derivados de óleo de mamona. SNM - PADCT - II, 76 p., 1994.

COSTA, C.A.S., MARCANTONIO, R.A.C., HEBLING, J., TEIXEIRA, H.M., KURAMAE, M. Biocompatibilidade de polímero de poliuretana vegetal derivada do óleo de mamona em estudo comparativo com cimento de óxido de zinco e eugenol. Avaliação histopatológica de implantes subcutâneos de ratos. Revista Odonto 2000. v. 1, n. 1, p. 44-48, 1997.

IGNÁCIO, H. Utilização do Cimento Derivado do polímero da Mamona no Preenchimento de Falha Óssea. Estudo Experimental em Coelhos. Dissertação de Mestrado Faculdade de Medicina - USP. Ribeirão Preto. 1995. 106 p.

IGNÁCIO, H. Avaliação da poliuretana da mamona nas formas compacta e porosa no preenchimento de falha óssea. Estudo experimental em cães. Tese de Doutorado. Faculdade de Medicina - USP. Ribeirão Preto, 1999, 92 p.

IGNÁCIO, H.; MAZZER, N.; BARBIERI, C. H.; CHIERICI, G. Uso da poliuretana derivada do óleo de mamona para preencher defeitos ósseos diafisários segmentares do rádio. Estudo experimental em coelhos. Revista Brasileira de Ortopedia, v. 32, n. 10, p. 815-821, 1997. desconhecido o tempo necessário para uma completa metabolização do polímero. Não se pôde determinar o tempo de metabolização neste experimento, uma vez que até a última observação o polímero ainda se fazia presente. Mas quando o polímero se apresentou em fragmentos menores, houve a aproximação de osteoclastos e sua fagocitose.

\section{Conclusões}

Nas condições do presente estudo e com base nos resultados obtidos, pode-se concluir que, histologicamente, não há rejeição ao polímero nos animais tratados, caracterizando biocompatibilidade e não ocorre reparação óssea nas lesões preenchidas com o polímero.

LAMANO CARVALHO, T.L., ALBUQUERQUEARAÚJO, C.A.C., TEÓFILO, J.M., BRENTEGANI, L.G. Histologic and histometric evaluation of rat alveolar wound healing around polyurethane resin implants. International Journal Oral Maxillofacial Surgery. v. 26, n. 2, p. 149152, 1997a.

LAMANO CARVALHO, T.L., TEÓFILO, J.M., ARAÚJO, C.A.C.A., BRENTEGANI, L.G. Chronology of alveolar healing following immediate implantation of Ricinus communis polyurethane resin: Histometric analysis in rats. Journal Biomedical Material Research. v. 37, n. 4, p. 449-452, 1997b.

LUNA, L.G. Manual of histologic staining. Methods of the Armed Forces Institute of Pathology. 3. ed, New York: Mc Graw, 1968, 258 p.

NÁCUL, A. M.; BORN, A. G.; FERNANDES, C. R.; DIAS, R. C. Utilização da membrana derivada de Ricinus communis nas rinoplastias primárias e secundárias. Nota prévia, 1998.

NAJJAR, T. A.; LERDRIT, W. e PARSONS, J. R. Enhanced osseointegration of hydroxyapatite implant material. Oral Surgery Oral Medical Oral Pathology v. 71, n. 1, p. 9-15, 1991.

OHARA, G. H.; KOJIMA, K. E.; ROSSI, J. C.; TELLES, M.; SOARES, T. V. C.; SALOMÃO, C.; SANDA, M. Estudo experimental da biocompatibilidade do polímero poliuretano da mamona implantada intraóssea e intra-articular em coelhos. Acta ortopédica brasileira. v. 2, n. 3, p. 62-68, 1995.

OLIVEIRA, M. F.; REZENDE, D.; UEDA, J. K. Estudo comparativo entre a reparação de um biomaterial baseado em poliuretana derivado do óleo de mamona e do osso autógeno implantados em sítios realizados na calvária de coelhos - análise histológica. Anais - $9^{a}$ Jornada Acadêmica de Araraquara. Unesp, p. 74, 1995.

OTA, K. Towards and ideal polyurethane graft for hemodialysis. Journal of biomedical material apllications. v. 4, p. 141-157, 1989.

PIERMATTEI, D. L.; GREELEY, R. G. Atlas de abordagens cirúrgicas aos ossos do cão e gato. 2. ed. São Paulo: Manole. 1988, 197 p.

SILVA, M.J.A. Estudo radiográfico das imagens convencionais e digitalizadas do comportamento do tecido ósseo frente ao implante do polímero de mamona em coelhos. Dissertação de Mestrado. Faculdade de Odontologia de Bauru - USP, 1997, $135 \mathrm{p}$.

TEIXEIRA, H. M. Reação a resina vegetal de mamona durante o processo de reparo em defeitos ósseos induzidos no corpo da mandíbula. Anais - 9 Jornada Acadêmica de Araraquara. Unesp, p. 117, 1995.

VILARINHO, R. H. Comportamento dos tecidos oculares frente ao implante de poliuretana vegetal. Anais - 9 a Jornada Acadêmica de Araraquara. Unesp, p. 105, 1995.

VILARINHO, R. H, HETEM, S., RAMALHO, L.T.O. Implante de resina de poliuretana vegetal na câmara anterior do olho de camundongo. Estudo histológico. Revista Odonto 2000. v.1, n.00, p. 25-29, 1996. 